\title{
Introducing Peer Review and Assessment within a Project Based Learning Framework to Account for Difficulty
}

\author{
Frank Kurzel \\ University of South Australia, Adelaide, Australia
}

Frank.Kurzel@unisa.edu.au

\begin{abstract}
In this paper, we report on a longitudinal study into instruction in a technology based course directed at the creation of multimedia applications. Students come from both the Computing and Media Arts areas and group project work has been the main assessment strategy employed. A metric referred to as the Difficulty was arrived at through a factor analysis of questionnaire data. This metric has been the focus of successive offerings of this action research. A disparity in this metric between students groups became evident and efforts have been employed in subsequent iterations of the course to appease these differences.

The project based instructional methodology that has been employed, is characterised by the giving of control over to the students during the development process. Peer review and assessment were also embedded within the instructional methodology to both provide exemplars of work conducted and subsequent feedback, and equity within the assessment process. A number of assessment rubrics were introduced to aid in this process. Interestingly, the end result was an movement on the Difficulty factor for the Computing students. Both cohorts agreed that the instructional methodology was satisfactory.
\end{abstract}

Keywords: Instruction, instructional methodologies, constructivist environments, project based learning, peer assessment, peer review.

\section{Introduction}

The current trend within tertiary institutions towards experiential learning paradigms and collaborative frameworks, necessitates consideration of the assessment practices undertaken and the role that they play in instruction. Assessment is an important aspect of instruction and provides an area where student involvement can be utilised to provide clarity to assessment requirements and alleviate misunderstandings.

Material published as part of this publication, either on-line or in print, is copyrighted by the Informing Science Institute. Permission to make digital or paper copy of part or all of these works for personal or classroom use is granted without fee provided that the copies are not made or distributed for profit or commercial advantage AND that copies 1) bear this notice in full and 2) give the full citation on the first page. It is permissible to abstract these works so long as credit is given. To copy in all other cases or to republish or to post on a server or to redistribute to lists requires specific permission and payment of a fee. Contact Publisher@InformingScience.org to request redistribution permission.
In this paper, we report on a longitudinal study into instruction in technology based courses where both peer and self assessment have been incorporated into the instructional process in and attempt to ameliorate some of the difficulties encountered by students of different backgrounds and interests. The skill sets required in these courses are diverse and call upon designers, media specialists 
and programmers to work collaboratively. Students come from both the Media Arts area and a range of computing degrees, including a 4 year multimedia/computing degree. Candidates for the development environment included Director and Flash; the former was used because of the internally developed resources and the stand alone nature of the final product.

This paper begins with an identification of the problem and an overview of the instructional methodology pursued in multimedia courses offered in the Media Arts program at the University of South Australia. An analysis of questionnaire data collected after an offering quantified a disparity between the two main student groups. Successive course offerings in this action research, have attempted to appease these differences; these are reported on and discussed. In the concluding section, the author discusses limitations of the research and suggests further strategies for addressing the documented challenges.

\section{The Problem}

Past experience (Kurzel \& Rath, 2007) with the course called Design for Interactive Multimedia, a second level course that employed the development of a multimedia project as the focus of the assessment, highlighted through the factor analysis of questionnaire data captured a the end of the course, 3 factors. These were referred to as:

\section{- Instructional Methodology is $\mathrm{OK}$ \\ - Group work is an issue \\ - Difficulty with the development}

Group work here referred to using groups in practical sessions to support learning and not working on a group project. Of concern here was the Difficulty with the development factor which suggested that part of the cohort had not coped with the project development, even though they generally responded that they were in favour of the instructional methodology employed. However, no means of identifying the cohort that responded in this manner was included in the questionnaire.

In a course called Creating Interactive Multimedia (third level) in the following semester, a similar questionnaire was used with the exception that an independent variable indicating the student's programme of study e.g. computing students, media arts etc., was introduced. A factor analys is was applied to the 31 item scale that came from the questionnaire. It was apparent that a 2 factor resolution, accounting for $35 \%$ of the overall variance was appropriate. A principal components analysis was the followed up with a factor analysis using an oblimin rotation. The factor loadings are shown in Table 1.

Table 1: Learning Environment Scale: Obimin Rotation Loadings

\begin{tabular}{|c|l|c|}
\hline Item & Statements & Loadings \\
\hline Factor 1 & Instructional Methodology is OK (eigen 5.219, variance 20.878) & \\
\hline 11 & I achieved more in this course than I thought I initially would & .791 \\
\hline 19 & $\begin{array}{l}\text { The instructional methodology provided me with enough scope to dis- } \\
\text { play my skills }\end{array}$ & .723 \\
\hline 7 & The assessment structure matched the structure of the course & .715 \\
\hline
\end{tabular}




\begin{tabular}{|c|c|c|}
\hline 2 & $\begin{array}{l}\text { The project based instruction in this course suited the way I like to } \\
\text { learn }\end{array}$ & .659 \\
\hline 12 & $\begin{array}{l}\text { The setting of weekly goals helped me focus on what needed to be } \\
\text { achieved. }\end{array}$ & .646 \\
\hline 23 & $\begin{array}{l}\text { I found being able to collaborate with my group in practical sessions } \\
\text { very helpful }\end{array}$ & .595 \\
\hline 8 & $\begin{array}{l}\text { The project enabled me to demonstrate the skills that I brought to the } \\
\text { group. }\end{array}$ & .582 \\
\hline 18 & $\begin{array}{l}\text { I was really satisfied with what the group ended up achieving in the } \\
\text { project work }\end{array}$ & .581 \\
\hline 13 & $\begin{array}{l}\text { I found the course initially challenging but managed to satisfy the pro- } \\
\text { ject requirements. }\end{array}$ & .546 \\
\hline 22 & I was given the opportunity to discuss and reflect on my learning & .545 \\
\hline 20 & The resources provided allowed me to satisfy the course requirements & .537 \\
\hline 24 & I enjoyed working on a project that was authentic. & .520 \\
\hline Factor 2 & Difficulty (eigen 3.476, variance 13.903 ) & \\
\hline 3 & I preferred working on the graphical design aspects of the course & .763 \\
\hline 4 & I preferred working on the Director scripting in the project (R) & .723 \\
\hline$\overline{14}$ & $\begin{array}{l}\text { An online helpdesk would have been helpful when I was working with } \\
\text { Director. }\end{array}$ & .687 \\
\hline 15 & $\begin{array}{l}\text { I have a good understanding of how to use Director to produce multi- } \\
\text { media pieces }(\mathrm{R})\end{array}$ & .621 \\
\hline 17 & $\begin{array}{l}\text { I like to be able to choose between a number of different media formats } \\
\text { representing content. }\end{array}$ & .619 \\
\hline 10 & $\begin{array}{l}\text { I would have liked to have a discussion forum with only my group } \\
\text { members }\end{array}$ & .519 \\
\hline
\end{tabular}

Notes:

(a) The response options. Scored 1 to 5, were as follows: strongly agree/ agree/ neutral/ disagree/ strongly disagree.

(b) Items score in reverse are shown by (R).

(c) $\mathrm{n}=50$

From factor 1 where the instruction was deemed favourable, students enjoyed the authentic project that formed the basis of the instructional methodology that was pursued. Collaboration, goal setting, discussion and reflection seemed to be tasks that were favourably reported on. It also appears that even though they were initially challenged, they came to terms with the project and its solution and thought they did better than their initial impressions.

Factor 2 highlighted difficulty with the development environment, in particular, the programming aspects required to satisfy the interactive elements of the project. It appears that other support mechanisms like online help and discussion forums would have been favourably looked upon. 
Both the InstructionOK and Difficulty factors were reduced and a $1 \mathrm{x}$ way ANOVA performed. The Arts students reported the work as relatively more difficult than the computing students with means of 2.31 and 3.04, $\mathrm{F}(1,45)=6.17, \mathrm{p}<.001$. Given that this course is situated in the Media Arts stream, this was significant. Both groups agreed on the acceptability of the instructional methodology with means of 2.24 and 2.37 respectively.

The instructor's responsibility then is to modify the instructional methodology in an attempt to ameliorate this disparity in the students' perception of the course.

\section{Background}

Instructional models can be placed in two broad categories: instructor-driven and based on cognitive learning theory, or student-driven and based on constructivist learning theory (Allert et al., 2002). Expository teaching lies in the first category. An instructor, in this case the lecturer, organises learning material into a hierarchical structure, starting with introductory material and building on those ideas using repetition and practice to reinforce principles. The instructor guides the learning, integrating new ideas with previously taught ideas. The content knowledge is delivered before a problem is introduced, allowing students to apply that attained know ledge to the problem (Wee 2004). University teaching has historically been in this format of lectures and tutorials.

On the other hand, the basis of constructivist learning theory is that

know ledge can be constructed personally, through reflection and relating new know ledge to prior experience, or socially, through interaction and discussion with others, such as teachers, other learners or family and friends. Either way, know ledge becomes personal and embedded within a context that is relevant to the learner's own life and experience. (Bates 2005, pp. 55-56)

Project Based Learning (Boud, 1985; Savin-Baden, 2003) as an instructional methodology, provides a good match to the aims of multimedia courses; students develop the knowledge, experience and skills for the creation of an effective multimedia piece through an authentic group project. It is closely linked to the problem based learning model and is grounded in constructivist learning theory. Problem based learning has traditionally been used to teach medical sciences where a problem is defined, researched, and reported on. In a multimedia course where the final outcome is an interactive game for example, the project becomes the problem and stages within the project become smaller problems that are inter-related and need to be satisfied.

Groups arrive at an idea for a game and create a specification known as the game treatment; design documents that include storylines, navigation structures, and complete storyboards follow. Production shells are developed, media items constructed, interface and instructional design principles utilised, game structures envisioned and software development suites employed. Implementation and project management issues then become fundamental to the construction of the final tested artefact. A discussion forum is used to allow for the posting of individual question and answers. These pertain generally to the development environment and any questions about the overall project specification. Project ideas and feedback are posted by the cohort in the early days to indicate the nature of the project being pursued.

Groups undertaking a Project Based Learning (PBL) instructional strategy meet an instructor periodically to facilitate the discussion on the learning issues at hand. This collaborative learning is integral to PBL with the communication being either face-to-face or on-line; the resulting process of negotiation attempts to resolve any outstanding learning issues. Hanrahan and Isaacs (2001) have argued that these self and peer-assessment skills are needed for students to develop life long 
learning skills; self-assessment helps students to set goals, and peer assessment can help them to contribute constructively in collaborative efforts.

\section{Ameliorating Difficulties}

A PBL instructional methodology was used in the course 'Creating Interactive Multimedia' in the first semester of 2007. Here the development of an interactive game formed the basis of a multiphase group project and constituted the major assessment component. A blended de livery mode that involved on-line materials, lectures and practicals, was used. Within the implementation, or production phase, students took more control on the tasks that each group member satisfied. Tasks were specified on a weekly basis with a review of performance occurring at week's end and a new set of goals established.

Groups were allowed to organise their own group's respons ibilities for the outcomes. That is to say, a student with extensive design skills for example, could be made responsible for the majority of the design aspects, and a computing student might be responsible for all the interactive elements. They would all need to have some understanding of how the production was to be managed and organised.

In an attempt to ameliorate some of these difficulties, the following instructional techniques were generally applied to the course work. Students were:

- actively encouraged to discuss programming aspects in groups

- given descriptive handler names in navigation tracking examples.

- encouraged to post questions

- exposed to script samples posted on the discussion forum

- encouraged to use explanatory internal documentation

Students were also encouraged to use AMLE (Kurzel, 2005), a locally developed porta/learning environment that contained a wealth of information and example scripts on Director Techniques. Search and Glossary features in-built into the information base could be used to access the content which was also provided in a range of media formats.

However, when the 2007 course data was analysed, no signif icant change occurred in the results. The Arts students still reported the work as relatively more difficult than the computing students with respective means of 2.39 and 2.87 .

A subsequent review of final grades for the courses indicated a $6 \%$ difference in the mean grades that were allocated to the two cohorts of students. Both assessment strategies included an individual report that could account for some differences. A summative peer assessment element existed for the group work; this was done at the end of the course and involved rating other group member's performance along with the ir own progress.

The following areas of performance were addressed in this peer evaluation:

- professional practice - attendance, punctuality, etc.

- involvement in group decision making and discussions

- knowledge of the project requirements

- quality of work produced.

One could argue that the computing students' who were typically involved in the programming and interactive elements, were perhaps being valued more than the arts students in the work that 
they conducted. A possible way of addressing this could be elaborate more on the elements that should be addressed, highlighting skills and know ledge for each assessment component.

The next iteration of the course that was offered in early 2008 had a small group of 20 students; a more elaborate set of assessment questions presented in rubrics were trialled for the peer assessment component. These were used at the end of each of the 3 assessment pieces; the first assessment piece (the proposal for the intended project), was used to familiarise students with their format. The interesting thing about this iteration was that one group appeared to be out of step with the others in terms of the quality of the work that was produced for the design aspects of the project. Again the groups worked in 'project' mode and were responsible for their group's decision about the format and quality of the work handed up.

Table 2: Factor Values 2006-2008

\begin{tabular}{|c|l|c|c|c|c|}
\hline Factors & & $\begin{array}{c}\text { 2006 } \\
\text { S2 }\end{array}$ & $\begin{array}{c}\text { 2007 } \\
\text { S1 }\end{array}$ & $\begin{array}{c}\mathbf{2 0 0 8} \\
\text { S1 }\end{array}$ & $\begin{array}{c}\text { 2008 } \\
\text { S2 }\end{array}$ \\
\hline \multirow{2}{*}{ InstructionOK } & Media Arts & 2.24 & 2.19 & 2.29 & 2.15 \\
& Computing & 2.37 & 2.34 & 2.52 & 2.44 \\
\hline \multirow{2}{*}{ Difficulty } & Media Arts & 2.31 & 2.39 & 2.24 & 2.24 \\
& Computing & 3.04 & 2.87 & 2.77 & 2.20 \\
\hline
\end{tabular}

In considering the results tabled in the Factor Values above, a peer review of assessable work as Falchikov (1996) has reported on, might have been an appropriate way to highlight inadequacies in the work while still providing time for these suggestions to be re-incorporated into assessable artefacts, and maintaining the goals of the instructional methodology.

\section{Another Iteration and Results}

In an attempt to address this perceived Difficulty aspect of the course encountered by Media Arts students again, all students were asked to become more involved with the development aspects. As the project was specified, each student took control of a component of the project; that is to say, each of the four students had the responsibility of designing and producing a quarter of the project; ideas, know ledge, techniques, etc. could still be shared within the group. This forced each student to produce a component of the project instead of being involved in one aspect e.g. the design of the interface.

The group decided on the aspects of the game play and arrived at the game play terminology defining the actions that could be consistently applied throughout the production to achieve the required functionality. They also decided on how the game could be represented internally within project. The project involved the creation of a $2 \mathrm{D}$ virtual environment where a computer forensic investigation was to be used to solve a crime. The audience for this game was to be 15 year olds and all tasks were to be simulated. To solve the crime, evidence would need to be collected requiring the use of an appropriate handler e.g. addToEvidence(Item). Initial shells of the production needed to only demonstrate the use of these calls; the details could be elaborated on later.

These abstractions were decided on by the group so that each member had some ownership of the game format and their possible use. Time was also spent organising the project into components that could be worked on independently, and an agile production model was pursued. Peer review was also introduced into the structure to allow feedback from others about initial designs and final productions. This feedback could then be acted upon if need be. Peer and self assessment at the group level was still employed with each assessment piece. 
The InstructionOK and Difficulty factors were reduced again and a $1 \mathrm{x}$ way ANOVA performed. The Arts students reported the work as slightly more difficult than the computing students with means of 2.24 and 2.20. Note that the response options were scored from 1 to 5 corresponding to strongly agree/ agree/ neutral/ disagree/ strongly disagree; the lower the number, the greater the agreement.

Both groups again responded favourably about the instructional methodology with little fluctuation in the ir respective means. One could argue however, that the media arts students favoured it more. It also appeared that the media arts group consistently found the content difficult while the computing students increasingly agreed with this in each subsequent offering. Either each new structure put into place to help the arts students confused the issue, or something else was having an effect. Significanlty however, both groups agreed with the notion that they had a good understanding of how to use Director to produce a multimedia piece.

\section{Conclusion}

It appears that shielding Arts students from the complexity of the development environment does not reduce the perception that it is too difficult to work in, neither does involving students in the decision making process, or abstracting over some of the details. By involving them in the development process however, Media Arts students hopefully get a more balanced view of the process and are able to participate constructively in all aspects of multimedia production.

A difficulty factor became apparent from questionnaire data collected in course evaluations and their appeared to be a marked difference in how students from different programs e.g. Media Arts and Computing, viewed the creation of interactive multimedia. When the responsibility for the production of a complete section instead of involvement in areas where they were best suited by their skill set, was coupled with an associated understanding of how each of the independent sections could be put together to form the project in total, the difference disappeared.

The role and benefit of peer review in this process can not be understated; having the ability of present the current state of an assessment piece and then to get constructive feedback from peers and the instructor that can then be incorporated within the production, has a positive result. Peer group assessment then provides a mechanism for a fair and equitable assessment strategy.

A limitation of this action research has been the reliance on quantitative data only; perhaps the results would have been more valid if they had been triangulated with other data from student interviews, classroom discussion and other student discussions. The intention is to employ these in the next iteration of the action research.

\section{References}

Allert, H., Dhraief, H., \& Nejd1, W. (2002). Meta-level category 'role' in metadata standards for learning: Instructional roles and instructional qualities of learning objects. COSIGN 2002 - The 2nd International Conference on Computational Semiotics for Games and New Media. Retrieved 5 May 2003 from $\mathrm{mttp}: / / \mathrm{ww}$.cosignconference.org/cosign2002/papers/Allert.pdf

Bates, A. W. (2005). Technology, e-learning, and distance education (2nd ed.). Abingdon, Oxon: Routledge.

Boud, D. (Ed.) (1985). Problem-based learning in education for the professions. Sydney: HERDSA.

Falchikov, N. (1996). Improving learn ing through critical peer feedback and reflection. Proceedings of the HERDSA Conference 1996 the Different Approaches: Theory and Practice in Higher Education, Perth, Western Australia. 
Kurzel, F., (2005). Customizing instruction. Proceedings of the Informing Science and IT Education Conference: InSITE 2005, Flagstaff, Arizona, June 16-19, 2005. Retrieved from http://proceedings.informingscience.org/InSITE2005/I26f97Kurz.pdf

Kurzel, F. \& Rath, M., (2007). Project based learning and learning environ ments. Journal of Issues in Informing Science and Information Technology (IISIT), 4, 503-510. Retrieved from http://proceedings.informingscience.org/InSITE2007/IISITv4p503-510Kurz397.pdf

Hanrahan, S. J., \& Isaacs, G. (2001). Assessing self- and peer-asses sment: The students' views. Higher Education Research and Development, 20(1), 53-70.

Savin-Baden, M. (2003). Facilitating problem-based learning: Illuminating perspectives. Berkshire, England: SRHE and Open University Press.

Wee Keng Neo, L. (2004). Jump start authentic problem-based learning. Singapore: Pearson Education South Asia.

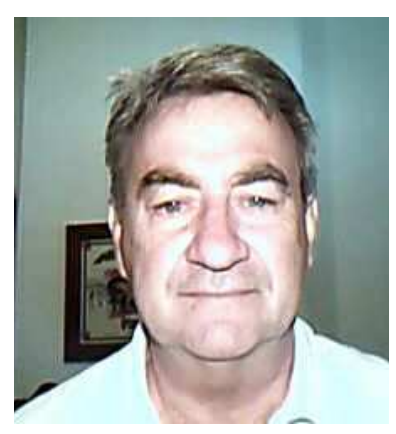

\section{Biography}

Frank Kurzel is a lecturer in the School of Communication, Information and New Media of the University of South Australia. He has been the Program Director for the Multimedia Studies Major within the Bachelor of Arts program at the University of South Australia. He has had extensive experience in Education, Computer Science and Multimedia areas. His research interests include web-based instructional systems to support his teaching, and the integration of Intelligent Tutoring Systems technology into hypermedia environments. He is also interested in instructional methodologies and enhancing the educational environment. 